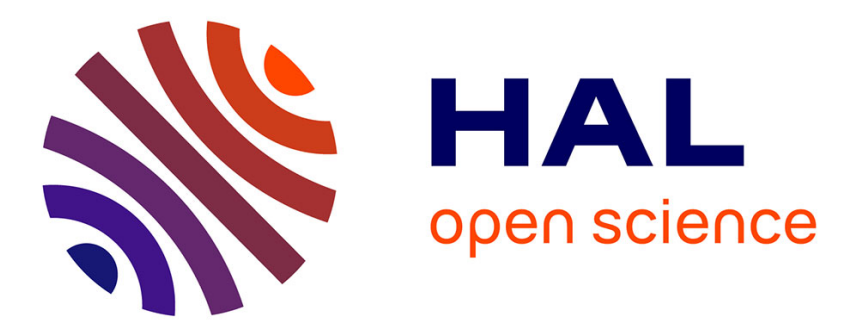

\title{
Qualitative features of polymer demixtion
}

P.-G. de Gennes

\section{To cite this version:}

P.-G. de Gennes. Qualitative features of polymer demixtion. Journal de Physique Lettres, 1977, 38

(21), pp.441-443. 10.1051/jphyslet:019770038021044100 . jpa-00231416

\section{HAL Id: jpa-00231416 https://hal.science/jpa-00231416}

Submitted on 1 Jan 1977

HAL is a multi-disciplinary open access archive for the deposit and dissemination of scientific research documents, whether they are published or not. The documents may come from teaching and research institutions in France or abroad, or from public or private research centers.
L'archive ouverte pluridisciplinaire HAL, est destinée au dépôt et à la diffusion de documents scientifiques de niveau recherche, publiés ou non, émanant des établissements d'enseignement et de recherche français ou étrangers, des laboratoires publics ou privés. 


\title{
QUALITATIVE FEATURES OF POLYMER DEMIXTION
}

\author{
P. G. DE GENNES \\ Collège de France, 75231 Paris Cedex 05, France
}

(Reçu le 27 juin 1977, révisé le 27 septembre 1977, accepté le 28 septembre 1977)

\begin{abstract}
Résumé. - Nous considérons trois types de points critiques associés à la ségrégation de chaînes polymériques longues et flexibles :

1) un polymère dans un mauvais solvant,

2) deux polymères fondus (sans solvant),

3) deux polymères dilués dans un bon solvant.

Pour tous ces cas, la théorie usuelle (Flory-Huggins) ou ses extensions, implique dès le départ un comportement de champ moyen et des exposants critiques classiques. Nous examinons la validité de cette description en appliquant un critère de Ginsburg. Dans les cas (1) et (3), on conclut que les exposants sont non-classiques. Dans le cas (2), la théorie de champ moyen est qualitativement correcte, sauf dans un très petit intervalle de température $\Delta T$ près du point critique $\left[\Delta T \sim T_{\mathrm{c}} N^{-\varphi}\right.$ où $N$ est l'indice de polymérisation].
\end{abstract}

Abstract. - We consider three types of critical points associated with the segregation of long, flexible, polymer chains :

1) one polymer + poor solvent,

2) two molten polymer species without solvent,

3) two dilute polymer species in a good solvent.

For all these cases the Flory Huggins theory (or its extensions) would lead to a classical (mean field) type of critical behaviour. We analyse the critical singularities more closely using a Ginsburg criterion, and conclude that in cases (1) and (3) the critical exponents are not classical. But in case (2), the Flory Huggins theory should apply, except for a minute temperature interval $\Delta T^{*}$ near the critical point $T_{\mathrm{c}}\left[\Delta T^{*} \sim T_{\mathrm{c}} N^{-\varphi}\right.$, where $N$ is the polymerization index, and $\varphi$ is a crossover exponent which we calculate for various situations].

Critical points in 3 dimensions are usually much more complex than predicted by mean field theory [1]. However, some special systems do conform with the mean field picture - the most prominent examples being superconducting metals [2] and superfluid helium 3 [3]; this simplification is related to the magnitude of the correlation length $\xi$

$$
\xi=\xi_{0}\left(\frac{T_{\mathrm{c}}}{\Delta T}\right)^{1 / 2} \quad \text { (mean field) }
$$

where $\Delta T$ is the distance to the critical point $T_{\mathrm{c}}$, and $\xi_{0}$ is the correlation length far from $T_{\mathrm{c}}$. Mean field behaviour is found near $T_{\mathrm{c}}$ whenever $\xi_{0}$ is large compared to the interparticle distance [4].

It is natural to ask if anything similar happens for critical points involving long polymer chains (with a polymerization index $N \gg 1$ ). The main practical complication here is due to polydispersity. In the present note, we ignore polydispersity and consider three typical situations (listed in the abstract) :

1) the case of a single polymer species dissolved in a poor solvent, at temperatures $T$ slightly below the $\Theta$ point [5], is the most familiar : the mean field free energy $F\left(\right.$ per $\left.\mathrm{cm}^{3}\right)$ as a function of concentration $c$ has the form $[5,6]$ :

$$
\frac{F}{T}=\frac{c}{N} \ln (c)+\frac{1}{2} v c^{2}+\frac{1}{6} w^{2} c^{3}+\cdots
$$

where $w=a^{3}$ is a monomer volume, and

$$
v \sim a^{3}(T-\Theta) / \Theta
$$

is weakly negative in the region of interest. From (2) one derives by standard methods [7] the osmotic pressure and the location of the critical point :

$-v_{\mathrm{c}}=2 w N^{-1 / 2}, \quad c_{\mathrm{c}}=w^{-1} N^{-1 / 2} \quad$ (mean field) 
and the correlation length $\left(\xi_{0} \cong N^{1 / 4} a\right)$ to be used in eq. (1) [8]. [Note that this value of $\xi_{0}$ leads to $\xi=a N^{1 / 2}$ when $T=\Theta$ exactly, as it should].

We now apply the Ginsburg criterion [9] to find out whether the mean field description is applicable near the critical point. We choose a point close to critical in the two-phase region, with equilibrium concentrations $c_{+}$and $c_{-}$. From eq. (2) we have [5] :

$c_{+}-c_{-} \cong W^{-1}\left|\Delta v c_{\mathrm{c}}\right|^{1 / 2},|\Delta v|=v_{\mathrm{c}}-v$.

We consider the corresponding numbers $v_{+}$and $v_{-}$ of monomers contained in a certain volume $\Omega$. We compare $v_{+}-v_{-}=\Omega\left(c_{+}-c_{-}\right)$to the fluctuations $\delta v$ in the total number. We know that [10]

$$
\delta v^{2}=c T \frac{\partial c}{\partial \pi} \Omega \cong|\Delta v|^{-1} \Omega .
$$

The importance of the fluctuations is measured by

$$
X=\left[\delta v /\left(v_{+}-v_{-}\right)\right]^{2}
$$

$X$ is maximal when $\Omega$ takes the smallest allowed value [9], namely $\Omega=\xi^{3}$ (or more generally $\Omega=\xi^{d}$ if we work in $d$ dimensions). Then we find

$$
X \cong\left(\frac{\Theta}{\Delta T}\right)^{2-d / 2} N^{1 / 2-d / 4} .
$$

For $d=3$ this reduces $X \sim\left[\left(\Theta-T_{\mathrm{c}}\right) / \Delta T\right]^{1 / 2}$ : thus $X$ is larger than unity throughout the tempe. rature interval $\Delta T \sim \Theta-T_{\mathrm{c}} \sim \Theta N^{-1 / 2}$ which is of interest for critical phenomena [5] : this means that the fluctuations are dangerous, and that the critical behaviour is not of the mean field type [9].

2) We turn now to a molten polymer blend $(\mathrm{A}+\mathrm{B})$ and consider for simplicity a symmetric situation $\left(N_{\mathrm{A}}=N_{\mathrm{B}}=N\right)$. It is convenient here to use a lattice model, the fractions of A and B per site being $\rho$ and $(1-\rho)$, and the effective interaction being

$$
U=U_{\mathrm{AB}}-1 / 2\left(U_{\mathrm{AA}}+U_{\mathrm{BB}}\right) .
$$

The mean field free energy per site $F_{\mathrm{s}}$ has the classical mixing form :

$F_{\mathrm{s}}=U \rho(1-\rho)+\frac{T}{N}[\rho \ln \rho+(1-\rho) \ln (1-\rho)]$.

Two cases appear to be of interest here :

(i) $U$ small, positive, and essentially temperature independent : this may occur in mixtures of deuterated and nondeuterated polymers of the same structure $\left({ }^{1}\right)$;

(ii) for chemically different species $U$ may be large and of either sign. To reach a critical point at a not too high temperature, we then need to have $U$ depen-

( ${ }^{1}$ I am indebted to Prof. Buckingham for an explanation of this effect. dent on $T$, and vanishing at one particular temperature $T_{0}$ : such a compensation point may indeed occur if A and B have very different thermal expansions. In this case, near $T=T_{0}$ we may set

$$
U=U^{\prime}\left(T_{0}-T\right)
$$

where $U^{\prime}$ is a constant of arbitrary sign (and of order unity).

From eq. (7) we derive the location of the critical point

$$
\begin{aligned}
U\left(T_{\mathrm{c}}\right) & =\frac{2 T_{\mathrm{c}}}{N} \\
\rho_{\mathrm{c}} & =1 / 2
\end{aligned}
$$

and the correlation length $\xi$ above $T_{\mathrm{c}}$ (eq. 1) with a prefactor

$$
\begin{array}{ll}
\xi_{0} \cong N^{1 / 2} a & \text { (case (i)) } \\
\xi_{0} \cong a & \text { (case (ii)) }
\end{array}
$$

The result for case (ii) is surprising at first sight. Note however that when $T=T_{0}$ (at the compensation point) $\Delta T \sim T_{0} / N$ and $\xi=\xi_{0}\left(T_{\mathrm{c}} / \Delta T\right)^{1 / 2}$ is of order $N^{1 / 2} a$, as it should for a system of molten chains without segregation effects.

We then proceed to construct the Ginsburg argument (in a volume $\Omega=\xi^{d}$ ) and find, for instance in case (ii) :

$$
\begin{gathered}
\left(v_{+}-v_{-}\right)^{2} \cong \Omega^{2} N \Delta T / T_{0} \\
\delta v^{2} \cong \Omega \Delta T / T_{0} \\
X=\frac{\delta v^{2}}{\left(v_{+}-v_{-}\right)^{2}}=N^{-1}\left(\frac{T_{0}}{\Delta T}\right)^{2-d / 2} \quad \text { (case (ii)) } .
\end{gathered}
$$

In particular, for $d=3, X$ is larger than unity only in a very small temperature interval

$$
\Delta T^{*} \cong T_{0} N^{-2} \cong\left|T_{0}-T_{\mathrm{c}}\right| N^{-1} \ll\left|T_{0}-T_{\mathrm{c}}\right| .
$$

For case (i) a similar argument leads to

$$
X=N^{1-d / 2}\left(\frac{T_{\mathrm{c}}}{\Delta T}\right)^{2-d / 2} \quad(\text { case (i)) }
$$

and for $d=3$ the width of the non classical region is

$$
\Delta T^{*} \sim T_{\mathrm{c}} N^{-1} \text {. }
$$

Thus for both cases we may say that the existence of long chains reduces the critical region very strongly.

The condition $|\Delta T|>\Delta T^{*}$ will be realized in most experiments as soon as $N$ is reasonably large : then the fluctuations are not dangerous, and the mean field picture is qualitatively correct.

3) The case of two (dilute) polymers dissolved in a good solvent is less familiar [11a]. One example (polystyrene + polyisobutylene + toluene) has recently been studied by light scattering and analysed in mean field $[11 b]$. We may summarize the situation as follows (again assuming symmetry between the 
two polymers $A$ and $B):$ the mean field free energy $\left(\right.$ per $\left.\mathrm{cm}^{3}\right)$ is :

$$
\begin{aligned}
\frac{F}{T}=\frac{1}{2} v_{\mathrm{AA}} c_{\mathrm{A}}^{2}+v_{\mathrm{AB}} c_{\mathrm{A}} c_{\mathrm{B}}+\frac{1}{2} v_{\mathrm{BB}} c_{\mathrm{B}}^{2} & \\
+ & \frac{T}{N}\left(c_{\mathrm{A}} \ln c_{\mathrm{A}}+c_{\mathrm{B}} \ln c_{\mathrm{B}}\right)
\end{aligned}
$$

where all three coefficients $v$ are positive and large (good solvent) but $v_{\mathrm{AB}}$ is larger than $v_{\mathrm{s}}=v_{\mathrm{AA}}=v_{\mathrm{BB}}$ :

a) At low concentration $c$ we have separate, swollen coils of radius $R_{\mathrm{F}}=a N^{3 / 5}$ [5]. In this regime, different coils avoid each other completely, and no segregation can take place.

b) At a concentration $c^{*}=N / R_{\mathrm{F}}^{3} \sim N^{-4 / 5} a^{-3}$ the coils begin to interpenetrate and the difference between $v_{\mathrm{AB}}$ and $v_{\mathrm{s}}$ is felt.

c) At a concentration of may be $2 c^{*}$ (or $3 c^{*}$ ) the effective interaction between two neighbouring coils $J$ becomes comparable to $T$, and segregation takes place. This statement may be understood from the scaling laws for single polymer solutions in good solvents [12] : for $c$ larger than $c^{*}$ the probability of contact between one given monomer and the others is not proportional to $c$ (as in the mean field theory) but to $c\left(c a^{3}\right)^{1 / 4}$, the last factor expressing the effect of correlations [12]. Then the effective coupling between two neighbouring chains is of order

$$
J\left(c^{*}\right) \sim T N c^{*}\left(c^{*} a^{3}\right)^{1 / 4}\left(v_{\mathrm{AB}}-v_{\mathrm{s}}\right) .
$$

Inserting the above formula for $c^{*}$ and $v_{\mathrm{AB}}-v_{\mathrm{s}} \sim a^{3}$ we are led to $J\left(c^{*}\right) \sim T$.

The analysis shows that the mean field picture is not very adequate for this case, since it does not even locate the critical concentration correctly $\left(c_{c}\right.$ is of order $N^{-1}$ in mean field while it is of order $N^{-4 / 5}$ in reality). What is needed here first is an improved mean field theory, where the effective couplings depend on concentration $(J(c))$. But as regards critical exponents, the situation is clear : just as in case (1) the interaction range is large, but the average distance between coils remains comparable to the interaction range : no special simplification is expected, and the critical exponents should be non-classical.

Acknowledgments. - The author is indebted to A. Vrij for pointing out the interest of situation (3), and the critical exponents should be non-classical.

\section{References}

[1] For a review on critical behaviour see STANLEY, H. E., «Introduction to phase transitions » (Oxford Univ. Press, London) 1971.

[2] See for instance : TINKHAM, M., "Introduction to superconductivity " (McGraw Hill) 1975, chap. 7.

[3] For an introduction to the superfluidity of $\mathrm{He}_{3}$ see LEGGETT, A., Rev. Mod. Phys. 47 (1975) 331.

[4] A simple version of the argument can be found in De Gennes, P. G., « Superconductivity of metals and alloys » (W. A. Benjamin N. Y.) 1966, p. 174-175.

[5] FloRY, P., Principles of polymer chemistry (Cornell University Press, Ithaca N. Y.) 1953, 194.

[6] We define concentrations as monomers $/ c a^{3}$, and we use units where Boltzmann's constant is equal to unity.

[7] A simple method to derive fluctuations and spatial correlation functions is the random phase approximation described (for polymers) in : JANNINK, G., DE GENNES, P. G. J. Chem. Phys. 48 (1968) 2260.

[8] This unusual value $\xi_{0}^{2} \sim N^{1 / 2}$ was missed by Debye. It is derived in De Gennes, P. G., Phys. Lett. 26A (1968) 313. Data on the real (non mean field) $\xi(N, T)$ are found in Chu, B., Phys. Lett. 28A (1969) 654.

[9] See Toulouse, G., Pfeuty, P., «Introduction aux groupes de renormalisation » (Presses Univ. Grenoble) 1975, p. 49.

[10] LandaU, L., Lifshitz, I., " Statistical physics » (Pergamon Press, London) 1958 , chap. 12 . In eq. (5) $\pi$ is the osmotic pressure.

[11a] Krause, S., J. Macros. Sci. Rev. Macros. Chem. C 7 (1972) 251.

[11b] VAN DEN Esker, M., VRiJ, A., J. Pol. Sci. 1943, 1953, 1967 (1976).

[12] DAoud, M. et al., Macromolecules 8 (1975) 804 